\title{
Solitary spinal metastasis of renal cell carcinoma and en-bloc resection-A case report.
}

\author{
Balgopal Karmacharya ${ }^{1}$, Nikunja Yogi ${ }^{1}$, Aabishkar Bhattarai ${ }^{2}$, Anjali Bhandari ${ }^{2}$, Prabin Bhandari ${ }^{2}$ Benju Tilija Pun $^{2}$ \\ ${ }^{1}$ Associate Professor, ${ }^{2}$ Medical Officer, Department of Neurosurgery, Manipal College of Medical Sciences, Pokhara, Nepal \\ Received: August 10, $2020 \quad$ Accepted: August 21, $2020 \quad$ Published: September 1, \\ 2020
}

Cite this paper:

Karmacharya B, Yogi N, Bhattarai A, Bhandari A, Bhandari P, Pun BT. Solitary spinal metastasis of renal cell carcinoma and enbloc resection-A case report. Journal of Brain and Spine Foundation Nepal. 2020;1(1):29-32.

Correspondence:

Balgopal Karmacharya

Associate Professor and Head of Department

Department of Neurosurgery

Manipal College of Medical Sciences, Pokhara, Nepal.

E-mail address: dr.balgopal@ hotmail.com

ORCID: https://orcid.org/0000-0002-6131-3516

\begin{abstract}
:
Renal Cell Carcinoma is a challenging condition for clinicians because of its poor response to radiotherapy, chemotherapy and even immunotherapy. Spine is the second most common site of metastasis and is also an indicator of poor prognosis. There is a significant dilemma for brain and spine surgeons about when to undergo aggressive surgical treatment, such as en-bloc resection of oligo-spine metastasis compared to conventional tumor excision by curettage. Here, we report a case of 60-year old female, a diagnosed case of renal cell carcinoma who had undergone right sided nephrectomy (with adrenalectomy) 5 years ago. She presented with history of pain over upper back. MRI revealed metastatic lesion over the thoracic T-7 vertebra. She underwent enblock total vertebral resection and reconstruction with titanium cage and pedicle screw fixation of the T-7 vertebra which healed with good results.
\end{abstract}

Keywords: Renal cell carcinoma, Spinal neoplasm, Spinal cord compression.

\section{Introduction:}

Renal cell carcinoma (RCC) is the seventh most common cancer in United States. ${ }^{1}$ Clear cell carcinoma, being the most common subtypes, accounts for $70 \%$ of renal tumors. One-third of the patients with renal cell carcinoma are diagnosed with metastatic disease. Even after nephrectomy, $25 \%$ of renal cell carcinoma have local recurrences or metastasis; with lungs being the most common site and osseous metastasis, particularly vertebral column, the second most common site. ${ }^{1}$ Skeletal metastasis brings a highly destructive lesion with osteolytic potential leading to significant pain, spinal cord compression and pathological fractures. Early diagnosis and prompt treatment reduce long term skeletal complications and morbidity.

\section{Case Summary:}

Mrs. JG, 60 years female from Pokhara, Kaski was admitted in Manipal Teaching Hospital on 17/06/2018 for evaluation of pain in the upper back for two months with increasing severity since last two weeks. . Pain was dull aching in nature, aggravated during walking, bending forward and relieved by lying down, with sometimes radiation to the left hypochondrium. There was no history of vomiting, trauma, weakness of any 
parts of the body, fever or any previous history of back surgery. She had undergone right sided nephrectomy (with adrenalectomy) with aorto- caval lymph nodes sampling five years back in India for renal cell carcinoma and was asymptomatic after that. She also had total abdominal hysterectomy 35 years back for menorrhagia. She had normal bowel and bladder habit and normal sleep and appetite. She used to have to normal non-vegetarian diet. She had no known allergy to any drugs or food. She was non-alcoholic and nonsmoker. She had been taking calcium tablets once a day after her nephrectomy. On examination she looked ill. There was no pallor, icterus, and lymphadenopathy. Blood pressure was 130/70 mm Hg, pulse $75 \mathrm{~b} / \mathrm{min}$, respiratory rate $15 / \mathrm{min}, \mathrm{SpO}_{2} 94 \%$ in room air and temperature $98.4^{\circ} \mathrm{F}$. There was tenderness over lower scapular region in the midline but there was no obvious swelling. She had normal neurological findings in both lower limbs. She had severe pain on turning on bed and on movements. Investigations revealed that her $\mathrm{Hb}$ was $11.9 \mathrm{gm} / \mathrm{dl}$, WBC- $11.6 \mathrm{x} 10^{\wedge} 3 / \mathrm{cu} \mathrm{mm}$, Platelet$295 \times 10^{\wedge} 3 / \mathrm{cu} \mathrm{mm}$, Sodium-139mEq/l, potassium $3.8 \mathrm{mEq} / \mathrm{l}$, Creatinine- $0.9 \mathrm{mg} / \mathrm{dl}$, urea- $18 \mathrm{mg} / \mathrm{dl}$, RBS$138 \mathrm{mg} / \mathrm{dl}$, Calcium- $6.9 \mathrm{mmol} / \mathrm{L}$, Magnesium 1.7mmol/L, fT3-2.10 pg/ml, fT4-1.41 ng/dl, TSH-0.90 $\mathrm{IU} / \mathrm{ml}$ and PT/INR-14.6 second/ 1.1. Urine analysis was normal and serology for HIV, HBsAg and HCV was negative. MRI scan of neck and chest showed no significant abnormality in screening FAT sat and DWI images. However, there was increased signal intensity within D7 vertebral body, compression fracture of D7 vertebra with compression of thecal sac anteriorly. CT of neck, chest, abdomen and pelvis revealed lytic lesion on the D7 vertebral body with enhancing epidural soft tissue component compressing the thecal sac anteriorly and tiny hypodense non-neoplastic cyst on right lobe of liver and degenerative changes in spine.

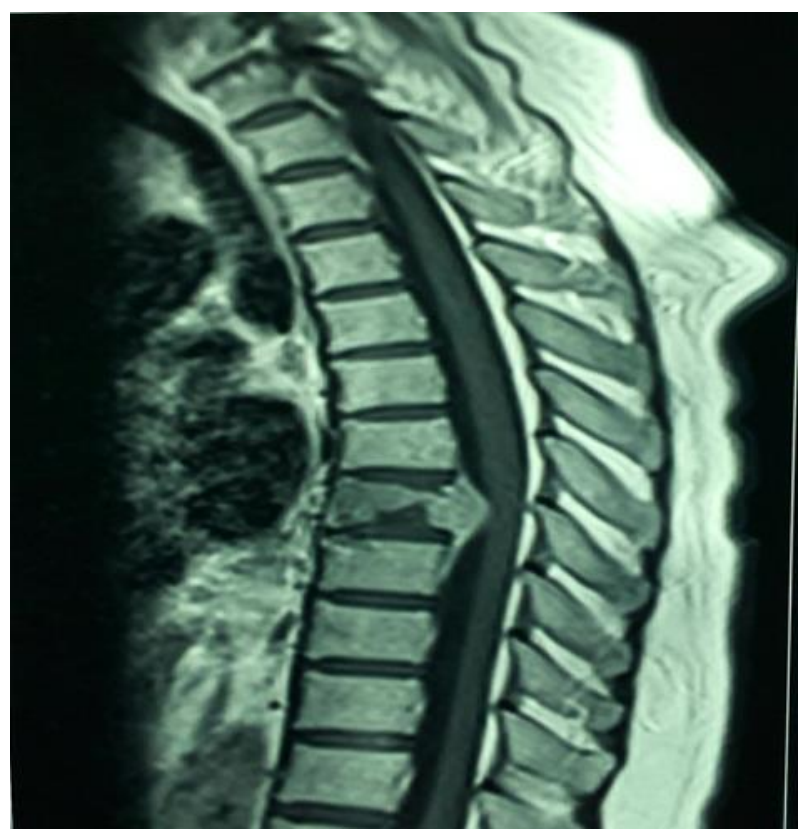

Figure 1: Collapsed D7 vertebra indenting anterior thecal sac.

On 22/06/2018, she underwent en block total vertebral resection and reconstruction with titanium cage and pedicle screw fixation (Figure 2). Postoperatively she developed cerebrospinal fluid leak from the wound on 4th day which was managed with lumbar subarachnoid drain for a week. Histopathological examination of the excised vertebrae revealed metastatic renal cell carcinoma. In two years follow up, the patient was doing fine (Figure 3).

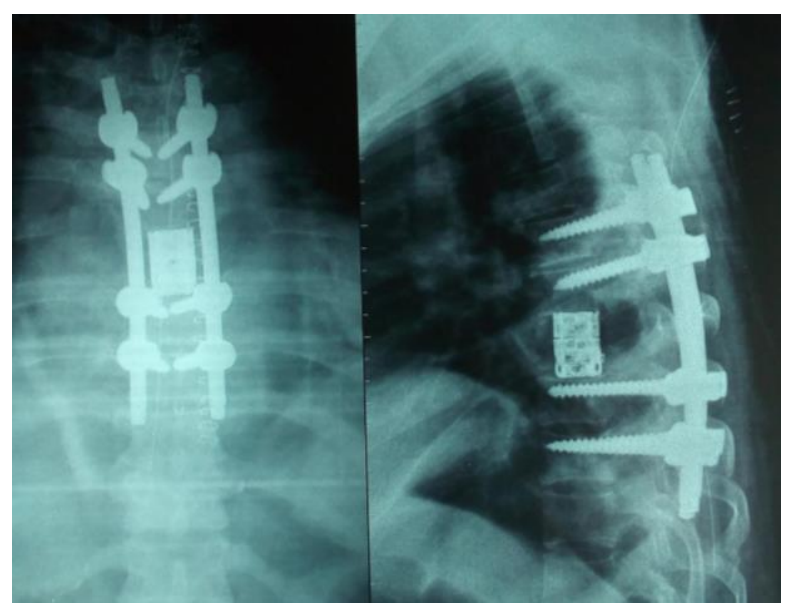

Figure 2: Postoperative radiograph showing titanium cage and pedicle screws. 


\section{Discussion:}

Renal cell carcinoma (RCC) is the 7th most common cancer in the United States. It accounts for around 3\% of adult malignancies and $90 \%$ of tumors arising from the kidneys.1. Annually one fifth of new cases of RCC result in death. Clear cell carcinoma is the most common type of RCC. RCCs are highly vascular with high metastatic potential. Even after nephrectomy 25\% of RCC recur locally or as metastatic disease. After the lungs, spine is the second most frequent site for metastases. Spinal metastasis remains an indicator of poor prognosis but some patients with oligo-metastatic spine disease can have long survival. Almost a third of patients with renal cell carcinoma have metastatic disease at the time of diagnosis.2 Skeletal metastases are common metastatic site after lungs. Twenty five to $50 \%$ of the metastases in renal cell carcinoma occur in the skeletal system.3 Such patients with osseous metastases have poor performance status due to pathological fractures, spinal cord compression and intractable pain. Approximately 10-20\% of recurrences in patients treated with nephrectomy for renal cell carcinoma (RCC) develop beyond 5 years after surgery (late recurrence). Lympho-vascular invasion, Fuhrman grade $3 / 4$, and a tumor stage $>$ pT1 are independent predictors of late recurrence after at least 5 year from surgery in patients with RCC.4

Pain is the most common presenting symptom followed by neurological deficits. Total surgical resection of the primary tumor and also the metastatic tumor is the only solution for long-term disease-free survival. Two larger studies on metastatic tumors of renal cell carcinoma indicated that complete resection of multiple renal carcinoma metastasis is associated with long-term survival.5 Osseous and spinal metastasis from renal cell carcinoma tend to be difficult to manage as they are large, highly destructive and hypervascular tumors.
Among the osseous metastases, spinal metastases is a significant risk factor in patient survival because of difficulty of a wider resection of the vertebral metastases.6 Conventional method of excision by curettage has been practiced but there is clear disadvantage of this approach as the chance of contamination of surrounding structures and residual tumor tissue at the site leading to early recurrence is high. About $70 \%$ of patients presenting with pain or neurological deficit improve following treatment.

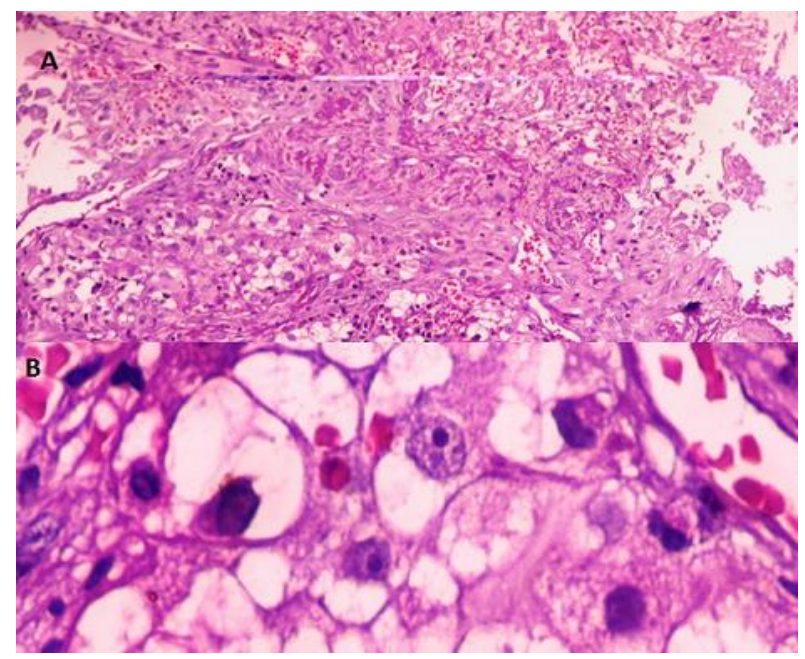

Figure 3 A. HPE of metastatic lesion in low power, B in high power showing metastatic clear cell renal carcinoma.

\section{Conclusion:}

The recurrences of renal cell carcinoma are high. One in four cases of surgically resected tumor recurs. This case report highlights the importance of long-term follow-up in RCC patients to detect local recurrence or distant metastasis which can be delayed for more than 5 years. It also emphasizes that en-block resection of oligo-spinal metastases should be carried out rather than conventional surgical curettage.

\section{References:}

1. Jemal A, Siegel R, Xu J, Ward E. Cancer statistics, 2010. CA Cancer J Clin. 2010 Sep-Oct;60(5):277-300. https://doi: 10.3322/caac.20073. 
2. Bukowski RM. Natural history and therapy of metastatic renal cell carcinoma: the role of interleukin-2. Cancer.

1997 Oct 1;80(7):1198-220. https://doi: 10.1002/(sici)1097-0142(19971001)80:7<1198::aidcncr3>3.0.co;2-h.

3. Negrier S, Escudier B, Gomez F, Douillard JY, Ravaud A, Chevreau C, et al. Prognostic factors of survival and rapid progression in 782 patients with metastatic renal carcinomas treated by cytokines: a report from the Groupe Francais d'Immunotherapie. Ann Oncol. 2002 Sep; 13(9):1460-8. https://doi.org/10.1093/annonc/mdf257.

4. Brookman-May S, May M, Shariat SF, Xylinas E, Stief C, Zigeuner R, et al. Features associated with recurrence beyond 5 years after nephrectomy and nephron-sparing surgery for renal cell carcinoma: development and internal validation of a risk model (PRELANE score) to predict late recurrence based on a large multicenter database (CORONA/SATURN Project). Eur Urol. 2013 Sep;64(3):472-7. 10.1016/j.eururo.2012.06.030.

5. Alt AL, Boorjian SA, Lohse CM, Costello BA, Leibovich BC, Blute ML. Survival after complete surgical resection of multiple metastases from renal cell carcinoma. Cancer. 2011 Jul 1;117(13):2873-82. https://doi: 10.1002/cncr.25836.

6. Kume H, Kakutani S, Yamada Y, Shinohara M, Tominaga T, Suzuki M, et al. Prognostic factors for renal cell carcinoma with bone metastasis: who are the longterm survivors? J Urol. 2011 May;185(5):1611-4. https:Ildoi: 10.1016/j.juro.2010.12.037. 